\title{
Uma análise antropológica das feiras internacionais do livro*
}

Brian Moeran**

* Recebido em: 09.04.2018. Aprovado em: 20.06.2018. Uma versão preliminar deste artigo foi publicada no Journal of the Royal Anthropological Institute, primavera de 2010. Tradução de José de Souza Muniz Jr.

** Professor aposentado e pesquisador independente. É Honorary Professor das Universidades de Hong Kong, Exeter e Zhejiang Gongshan. Email: bdmoeran@hku.hk
Resumo: As feiras internacionais do livro são extremamente importantes pela luz que jogam sobre a organização e a estrutura da indústria editorial. Primeiramente, as feiras mais importantes tendem a coincidir com o ciclo do livro: os editores vendem suas listas de primavera nas feiras que ocorreram no outono anterior (por exemplo, Frankfurt), e suas listas de outono nas feiras da primavera (como Londres e Bolonha). Em segundo lugar, as feiras do livro reúnem todos os membros da cadeia de suprimentos e de valor da indústria editorial, proporcionando a eles uma ocasião única para a interação face a face. Terceiro, elas dão uma estrutura visível ao campo editorial e reforçam essa estrutura, ao mesmo tempo em que tornam visíveis os vários recursos (capital econômico, humano, simbólico intelectual) controlados por diferentes editoras no espaço estruturado de posições em que se movem. Como os participantes competem po esses recursos, as feiras de livros podem ser vistas como um torneio de valores.

Palavras-chave: torneio de valores, evento configurador de campo, Feira do Livro de Londres, Feira do Livro de Frankfurt.
Abstract: International book fairs are extremely important for the light they throw on the publishing industry's organization and structure. First, the most important fairs tend to coincide with the book cycle. Publishers sell their spring lists at fairs held the previous autumn (e.g. Frankfurt), and their autumn lists at fairs held in the spring (e.g. London, Bologna). Second, book fairs bring together all members of the supply and value chains in the publishing industry, and provide a unique occasion for them to interact face-to-face. Third, they also give a visible structure to the publishing field, thereby reinforcing that structure, while making visible the various resources (economic, human, symbolic and intellectual capital) commanded by different publishers in the structured space of positions in which they operate. Because participants compete for such resources, book fairs may be seen as constituting a tournament of values.

Keywords: tournament of values, field configuring event, London Book Fair, Frankfurt Book Fair. 
1 A observação participante foi realizada nas feiras de Frankfurt (2007 e 2009), Londres (2008) e Tóquio (2009), nas quais participei de reuniões entre editores da Berg com representantes, distribuidores, editores etc. durante três dias (2007 e 2008), e também no estande da Independent Publishers Guild, além de acompanhar de modo passageiro a United Publishers, uma distribuidora japonesa, em Frankfurt, por um dia (2009). Também visitei a Reed Exhibitions em Richmond por um dia em fevereiro de 2008, e conversei com a equipe responsável pela Feira do Livro de Londres. Depois, fui autorizado a segui-los pelo local da feira no Earls Court e observá-los lidando com a organização da feira no dia anterior à inauguração. Também conversei com os responsáveis pela organização da Feira do Livro de Frankfurt.

\section{Introdução}

Com base em um intensivo trabalho de campo nas feiras do livro de Frankfurt, Londres e Tóquio, este trabalho descreve o papel das feiras internacionais do livro na indústria editorial e analisa de que modo, ao reunir participantes em interações face a face de curta duração num ambiente estruturado, elas definem e reafirmam os valores econômicos, sociais e simbólicos que constituem o campo editorial de modo mais amplo ${ }^{1}$.

Em muitos aspectos, as feiras internacionais do livro preenchem os requisitos estabelecidos por Arjun Appadurai (1986: 21) em sua discussão seminal sobre os "torneios de valor". Os critérios que ele estabelece no que diz respeito ao afastamento espaçotemporal desses torneios com relação à rotina da vida econômica cotidiana, às disputas por status realizadas pelos participantes e à relevância dos seus resultados para o cotidiano ordinário, são todos aplicáveis ao caso das feiras do livro. Esses eventos também se enquadram na discussão de Bourdieu sobre os campos de produção cultural e seus mecanismos de consagração e homologia estrutural entre as obras, as posições e as tomadas de posição, na medida em que os participantes procuram aproveitar as oportunidades disponíveis num campo específico (Bourdieu, 1993: $84,133,182)$.

Embora o próprio Appadurai estivesse interessado principalmente no circuito do kula na Melanésia como um exemplo de torneio de valor, ele claramente admitiu que "um ethos agonístico, romântico, individualista e à moda de jogo que está em contraste com o ethos do comportamento econômico cotidiano" (Appadurai, 1986: 50) pode ser encontrado em sociedades industrializadas contemporâneas. Em resposta ao seu apelo para "um exame mais completo dos modos de articulação dessas economias de "torneio"” (ibidem), eu próprio argumentei que os torneios de valor também incluíam:

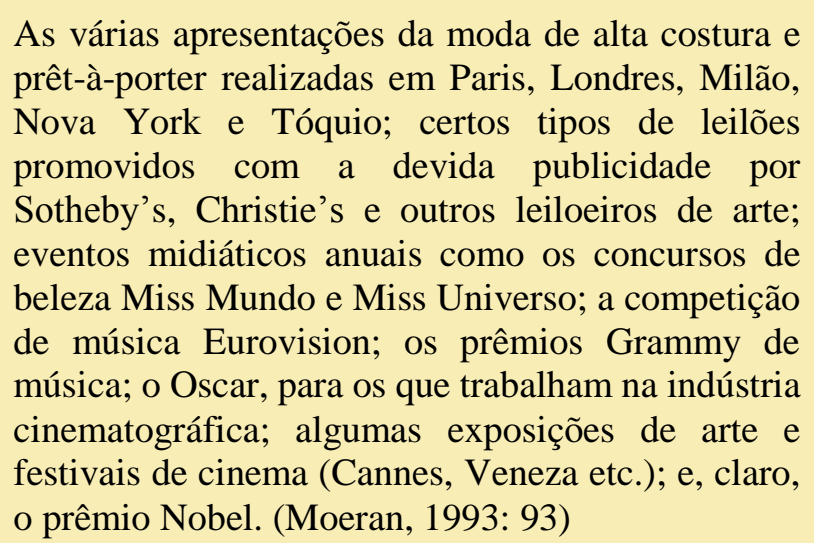

Alguns desses exemplos foram estudados pelos autores de um volume dedicado ao tema (Moeran e Pedersen, 2011). Além disso, outras publicações abordam diferentes competições, honrarias, prêmios (Anand e Watson, 2004; Anand e Jones, 2008; Glynn, 2008), feiras (Entwistle e Rocamora, 2006; Skov, 2006; Thompson, 2008) e festivais (Barbato e Mio, 2007; Evans, 2007), em várias indústrias criativas. Ao mesmo tempo, as diferentes origens disciplinares desses autores trasladaram a discussão dos "torneios de valor" para os "eventos de configuração de campo" (Lampel e Meyer, 2008).

Dossiê Práticas Editoriais e Intermediações da Cultura

Arquivos do CMD, Volume7, N.1. Jan/Jun 2018 
Este artigo analisa as feiras internacionais de livros no âmbito de uma aliança talvez um pouco desconfortável entre essas diferentes disciplinas. $\mathrm{O}$ argumento central desenvolvido aqui é que as ideias inspiradoras de Appadurai precisam ser retomadas integralmente, em vez de serem apenas desenvolvidas em parte, como tem ocorrido.

\section{A indústria editorial}

A publicação de livros é uma atividade comercial que consiste em colocar livros à disposição do público (Feather, 2006: 1), e as editoras são "organizações de risco que adquirem conteúdo e estão orientadas à produção de um tipo particular de mercadoria cultural" (Thompson, 2005: 15). Elas atraem um enorme número e variedade de autores que querem comunicar suas ideias e ser reconhecidos por elas. Uma característica marcante da indústria editorial em relação a outras indústrias culturais ou "criativas" (Caves, 2000) é o número singular de novos produtos lançados todos os anos: são cerca de 250 mil novos títulos apenas em língua inglesa e 1 milhão de títulos impressos no total (incluindo reedições).

As principais dificuldades que as editoras enfrentam são adquirir conteúdos e crescer. Em outras palavras, elas têm que cultivar autores, por um lado, e depois, para publicar os manuscritos dos autores, precisam pagar com antecedência os custos editoriais, de produção e de impressão - para não mencionar os adiantamentos aos autores. Apenas meses depois (em geral metade de um ano) é que se cobrem esses custos - e, com sorte, geram-se lucros - por meio do varejo. No entanto, o fato de que os novos produtos são, via de regra, não testados faz com que seja difícil prever os retornos. Portanto, a edição implica tomadas de decisão de alto risco. Sem capital, uma editora não é capaz de aumentar o número de títulos publicados a cada ano - o que significa que, para crescer, ou ela tem de produzir um grande sucesso, ou ela precisa aumentar seus investimentos.

Os editores são mais do que intermediários entre autores e leitores. Eles encomendam manuscritos e financiam a produção, o marketing, a promoção e as vendas - de modo muito semelhante aos galeristas do mundo da arte, descrito por Don Thompson (2011). Nesse processo, eles conferem autoridade e agregam valor ao trabalho dos autores (Clark, 2001: 3). Em seu excelente estudo sobre a publicação de livros acadêmicos, John Thompson usa três conceitos que nos ajudam a entender a organização e a estrutura desse setor. O primeiro deles é o ciclo de publicação, que abrange os estágios (tipicamente são quatro) que um livro percorre da contratação do manuscrito ao produto acabado. Esse ciclo é dividido em duas temporadas e, para a maioria das editoras, a front list - ou seja, o conjunto de títulos publicados durante o ano anterior corresponde ao volume de negócios que paga as despesas de produção. Normalmente, $20 \%$ dos títulos são responsáveis por cerca de $80 \%$ da receita (Thompson, 2005: 16-20). No entanto, os editores precisam desenvolver também uma back list, isto é, um conjunto de livros que continuam sendo vendidos após o primeiro ano. São eles 
${ }^{2} \mathrm{O}$ capital simbólico ajuda o editor a posicionar e promover novos livros e atrair novos autores. Sustenta, portanto, as relações de confiança no campo editorial (Thompson, 2005 33), embora os próprios autore também acumulem capital simbólico.

que fornecem um retorno contínuo e, assim, ajudam um editor a crescer e assumir riscos em novos títulos.

O segundo conceito é o de cadeia editorial - o conjunto de organizações interconectadas que estão envolvidas na publicação, venda e distribuição de livros -, na qual cada elo fornece um serviço, ao qual os outros elos atribuem algum valor. A cadeia editorial abrange, assim, tanto uma cadeia de suprimentos como uma cadeia de valor. Cada um dos elos supostamente acrescenta algo de valor no decorrer da cadeia, e os intermediários (como os agentes literários e os empacotadores de livros) podem servir para criar conteúdo. As principais atividades do editor são adquirir (e desenvolver) conteúdos e construir um catálogo; fazer investimentos financeiros e estar preparado para assumir riscos; avaliar a qualidade de um texto e garantir que ele atenda a certos padrões; e cuidar das vendas e do marketing (Thompson, 2005: 20-6).

Há cinco passos principais na cadeia de suprimentos, e é a relação entre diferentes partes em cada estágio que faz as coisas funcionarem. O primeiro passo é externo, entre autor e editor, que pode contratar até sessenta títulos por ano. Em seguida, há a relação interna entre o editorial e os departamentos de vendas e marketing, na qual os editores tentam vender suas ideias levando em consideração a adequação ao catálogo, o nome do autor, os diferenciais do livro com relação à concorrência, seu potencial para integrar a back list ou a front list, e assim por diante (Clark, 2001: 85-6; cf. Powell, 1985: 183-5). O terceiro passo é a relação, por um lado, entre o marketing e outros editores (para os quais o editor original vende direitos) e, por outro, entre o marketing e os representantes que distribuem e colocam os livros em pontos de venda. Depois, esses representantes fazem a ligação com as livrarias e fornecedores de bibliotecas, que, finalmente, mantêm relações com suas respectivas clientelas.

Em terceiro lugar, está o conceito de campo editorial, que consiste no "espaço estruturado de posições em que diferentes editores, agentes e outras organizações estão localizados" (Thompson, 2005: 16). Na verdade, trata-se de vários (sub)campos justapostos, uma vez que diferentes tipos de produção (livro didático, de interesse geral, acadêmico e assim por diante) são organizados de forma bastante diferente, com uma grande variedade de propriedades linguísticas, espaciais e tecnológicas. Thompson argumenta que os editores possuem quatro tipos de recursos: capital econômico (composto de recursos financeiros acumulados); capital humano (o pessoal empregado e seus conhecimentos); capital simbólico (prestígio, reconhecimento e consagração acumulados, oriundos da atividade dos editores como intermediários culturais e árbitros da qualidade e do gosto ${ }^{2}$; e, finalmente, capital intelectual (acumulado de acordo com os direitos que a editora possua ou controle). $\mathrm{O}$ estoque de contratos com autores que uma editora detém "representa a soma total dos direitos que possui sobre o conteúdo intelectual que busca adquirir, desenvolver e transformar em commodities comercializáveis, mais comumente livros" (Thompson, 2005: 34). De fato, os principais ativos financeiros de um editor existem de acordo com seu acesso a e seu controle sobre os direitos

Dossiê Práticas Editoriais e Intermediações da Cultura

Arquivos do CMD, Volume7, N.1. Jan/Jun 2018 
de propriedade intelectual contemplados pelos contratos - uma questão à qual voltarei na conclusão deste artigo.

\section{As feiras do livro}

As feiras do livro estão entre os vários eventos dos quais diferentes players da indústria editorial participam adquirindo conteúdos e assumindo riscos financeiros. Elas são importantes pontos nodais da indústria editorial global e estão situadas em interfaces específicas - tipo de livro (infantil, culinária, viagens etc.), segmento de mercado (interesse geral, acadêmico, colecionismo etc.) e dispersão geográfica da indústria (diagramadores na Índia, impressores em Hong Kong etc.) - na cadeia de valor (cf. Skov, 2006: 765).

Como parte de suas atividades rotineiras de vendas, uma editora participa de: conferências acadêmicas, onde se reúne com autores (em potencial) e adquire conteúdos, além de fazer vendas; sessões de formação especializada (em especial para o desenvolvimento de sistemas eletrônicos); conferências de bibliotecários (onde pode conhecer as necessidades das bibliotecas para desenvolver e modificar suas plataformas de vendas pela internet); grupos de usuários e fóruns semelhantes (como a conferência da associação de editores independentes), que permitem ao editor compartilhar seu próprio conhecimento e aprender com outros agentes da cadeia editorial.
As feiras internacionais de livros são extremamente importantes por iluminar a organização e a estrutura do setor editorial. Embora sejam realizadas em diferentes partes do mundo durante $\mathrm{o}$ ano inteiro, duas das maiores feiras internacionais coincidem com o ciclo do livro: a Feira do Livro de Londres (LBF), em abril, e a Feira do Livro de Frankfurt (FBF), em outubro, ambas anuais. Por isso, os editores tendem a comercializar seus catálogos de primavera em feiras realizadas no outono anterior, e suas listas de outono em feiras realizadas na primavera (Owen, 2006: 86).

Além disso, essas feiras reúnem todos os membros das cadeias de suprimento e de valor na indústria editorial, o que as torna uma ocasião única para que eles interajam de modo presencial. Por fim, elas tornam visível a estrutura do campo editorial, reforçando essa estrutura ao tornar visíveis os vários capitais (econômicos, humanos, simbólicos intelectuais) que os diferentes editores controlam no espaço estruturado de posições em que operam.

As feiras do livro, como as conhecemos hoje, surgiram logo após a Segunda Guerra Mundial, quando primeiro Leipzig (1946) e depois Frankfurt (1949) restabeleceram uma feira anual cujas origens remontam aos séculos XII e XIII (Flood, 2007; Weidhaas, 2007). Daí em diante, houve um aumento constante no estabelecimento de feiras internacionais do livro em todo o mundo, que agora formam uma rede ou um "cluster cíclico" de feiras (Power e Jansson, 2008). Varsóvia (1956) foi a primeira cidade a sediar uma feira de livros fora da Alemanha, rapidamente seguida por Belgrado e Toronto (1957) e pela feira do livro infantil de Bolonha (1964). Em

Dossiê Práticas Editoriais e Intermediações da Cultura

Arquivos do CMD, Volume7, N.1. Jan/Jun 2018 
${ }^{3} \mathrm{O}$ envolvimento da mídia em feiras e festivais é crucial tanto para a publicidade quanto para a criação de uma imagem positiva do evento (Mossberg e Getz, 2006, p. 321).

${ }^{4}$ A feira está aberta ao público em geral somente aos sábados e domingos. Além da reputação da feira, é esse tipo de estatística que um participante em potencial usa para avaliar se deve ou não participar do evento (cf. Berne e García-Uceda, 2008: 567).

${ }^{5}$ As únicas pessoas no mundo editorial que, via de regra, não frequentam as feiras do livro são os editores. O autores também costumam evitar as feiras. Como disse um informante: "Ter um autor na Feira do Livro de Londres seria como dar às vacas uma visita guiada a Smithfield". (N.T.: A citação do informante faz referência à Smithfield Foods, uma grande empresa norte-americana de processamento de carne e derivados.)

${ }^{6}$ N.T.: Distrito localizado na região leste de Londres, onde se localiza o porto. Considerada uma área degradada da cidade, após ter passado por um processo de requalificação urbana nos anos 1980 ela tornou-se uma zona de atração comercial e boom imobiliário.
1972, foi criada a London Book Fair, seguida pela de Buenos Aires, em 1974. A década de 1980 viu surgir uma infinidade de feiras, começando com o Salão do Livro de Paris (1981), seguido por lugares tão distantes como Istambul (1982), Gotemburgo (1985), Guadalajara (1987) e Teerã (1988). Na década de 1990, a rede se espalhou para o Oriente Médio e a Ásia, com feiras estabelecidas em Abu Dhabi (1991), Hong Kong (1990), Tóquio (1994) e Pequim (1995), e na primeira década do novo milênio novas feiras do livro foram inauguradas em Bangkok (2003), Bucareste (2006), Cidade do Cabo (2006), Salônica (2006), Kuala Lumpur (2008) e Viena (2008), entre outras cidades. A feira do livro é, agora, um evento internacional por meio do qual uma cidade se torna "um nó no mosaico global e no calendário anual" da edição (Weller, 2008: 111), e a rivalidade entre feiras, existente já nos tempos medievais existem até hoje (cf. Flood, 2007: 8).

De todas elas, a de Frankfurt (FBF), organizada por uma subsidiária da alemã Publishers and Booksellers Association, é a maior e mais importante. Acontece no recinto ferial da cidade (Frankfurter Messe), ocupando anualmente todos os seus doze salões durante a segunda semana de outubro, de quarta a domingo. Em 2006, contou com 7.272 expositores, representando 113 países, com a exibição de 382.466 publicações, das quais 111.913 eram novos títulos. Durante a feira, ocorreram 2.700 eventos de algum tipo, cobertos por 11 mil jornalistas credenciados, de 66 países $^{3}$. Ao todo, a feira foi visitada por 286.621 pessoas, das quais 183 mil a negócios ${ }^{4}$.
Tal como a maioria das grandes feiras internacionais de livros, a FBF é um evento comercial, e não um festival para escritores. É vista como a mais importante feira do livro do mundo para a compra de direitos internacionais, licenciamentos e outras negociações. Como muitas outras feiras de livros, também é um local essencial para o lançamento de novos livros e de novidades da indústria, e oferece uma oportunidade para os participantes conduzirem suas próprias pesquisas de mercado sobre o que está sendo publicado e por quem. Dela participam todos os que fazem parte da cadeia de valor - editores, agentes literários, livreiros, bibliotecários, acadêmicos, ilustradores, prestadores de serviços, produtores de filmes, tradutores, impressores, associações profissionais e comerciais, artistas, autores, colecionadores e fornecedores de software e multimídia ${ }^{5}$.

Algumas dessas feiras são promovidas por empresas que organizam eventos internacionais. A própria FBF tem sido ativa na criação de feiras de livros ao redor do mundo, em lugares como Abu Dhabi e Cidade do Cabo, e quase assumiu as rédeas da feira de Londres depois de uma mudança desastrosa para as Docklands ${ }^{6}$. Outra empresa que organiza eventos é a Reed Exhibitions, que possui em seu portfólio mais de 500 feiras comerciais ao redor do mundo, atendendo 47 setores, que vão da indústria aeroespacial e aeronáutica à de joias, passando pelas de energia, petróleo e gás; eletrônica e engenharia elétrica; esportes, lazer e saúde; viagem; e livros e publicações. A Reed organiza a Feira do Livro de Londres (desde 1986), a BookExpo America, a BookExpo Canada, o Salão

Dossiê Práticas Editoriais e Intermediações da Cultura 
do Livro de Paris, a Feira Internacional do Livro de Tóquio e, desde 2008, a feira de Viena. Trabalha de maneira estreita com as associações comerciais, as autoridades municipais e as organizações governamentais ou semigovernamentais (como o British Council, com quem colabora para organizar os temas anuais de país na feira de Londres).

Embora a Frankfurt Buchmesse venha desempenhando um papel ativo em ajudar a estabelecer algumas dessas feiras, nem todas elas seguem a estrutura da FBF. Enquanto algumas delas - como as de Bolonha, Londres e Guadalajara - tentaram estabelecer-se como eventos voltados à negociação de direitos internacionais, outras como as de Varsóvia, Pequim e Teerã - são nacionais e visam a atender os mercados domésticos, muitas vezes incluindo o público em geral. Outras, ainda, como a BookExpo America, concentram-se quase exclusivamente em direitos de distribuição. Como resultado disso, editores e outros expositores classificam as várias feiras de forma diferente, dependendo do que estão procurando. De um modo geral, no entanto, há um consenso de que a feira de Frankfurt é a número um no quesito "internacionalismo", seguida pela de Londres e, em seguida, pelas de Bolonha (para livros infantis) e de Guadalajara (para direitos espanhóis). A FBF se destaca de todas as outras feiras porque acontece em um local dedicado exclusivamente a feiras comerciais; porque o governo local investiu nela, algo que não é verdade para o caso de Londres, por exemplo; e porque é extremamente bem organizada.

\section{As atividades diárias da feira}

Então, o que acontece numa feira do livro e por que as pessoas vão até lá? Em que tipo de atividades elas participam, fazendo da feira um torneio de valores? Evidentemente, as feiras de livros proporcionam a seus expositores e visitantes um ambiente altamente flexível e de baixo custo, onde elas podem alcançar uma ampla gama de objetos de vendas e de marketing - desde a aquisição de um potencial best-seller à venda de direitos de filmes, por meio da nomeação de um novo representante de vendas, da construção de uma imagem de marca, da verificação daquilo que os concorrentes estão fazendo, ou até mesmo da venda de uma empresa. Mais importante que tudo isso, as feiras oferecem aos participantes a oportunidade de encontrar face a face e, assim, estabelecer e construir relações comerciais.

Frankfurt oferece uma visão panorâmica do mundo editorial - quem continuou, quem vendeu para quem, e assim por diante. $\mathrm{O}$ mais importante são as relações. As feiras são a única chance de interação presencial, onde podemos explicar tudo sobre a nossa empresa e sobre o que fazemos. As pessoas tendem a ficar confusas no e-mail. Você também cria amizades com pessoas nas feiras, e isso não necessariamente gera benefícios comerciais diretos imediatamente, mas uma pessoa pode te indicar para outra. Como resultado, para alguns, acontece muito de pós-estratégia. (Naveen Kishore, diretor geral da Seagull Books)

A feira é o lugar onde você dá cara aos nomes. Em lugares como Frankfurt e Londres, você faz novas parcerias comerciais. Eu fiz umas vinte ou trinta nos 
${ }^{7}$ N.T.: Uma das maiores cadeia de livrarias do Japão, com lojas em vários três anos em que estive lá representando a Berg, graças às pessoas que encontrei lá. Vários desses pedidos - que hoje valem cerca de 50 mil libras por ano - podem vir três meses depois ou até mais, po meio de amigos de amigos. Como quando seu contato de Cingapura te conta sobre a Kinokuniya em Dubai, e os pedidos vêm dessa maneira. Fazer contatos é um aspecto crucial de qualquer feira do livro. (Veruschka Selbach, ex-gerente de vendas da Berg Publishers)

As feiras de livros são extremamente importantes, porque muitas negociações de direitos são baseadas em contatos pessoais, que devem ser construídos a longo prazo para que você se torne o primeiro porto de escala para um contato que está buscando algo específico. Você passa a conhecer os gostos dos seus contatos e sabe, por exemplo, para quem enviar uma proposta de direito de tradução na Itália ou na Venezuela. Não importa o que digam: o e-mail não pode tomar o lugar das feiras de livros, porque la você tem a oportunidade de sentar-se frente a frente com uma pessoa por trinta minutos e manter uma conversa. (Lynette Owen, diretora de direitos autorais da Pearson Education)

Além disso, as feiras fornecem informações a seus participantes:

As feiras de livros te dão notícias super frescas que você só receberia por e-mail uns dois meses depois. A gente precisa falar com as pessoas, porque a fala não é tão pesada quanto a escrita. Isso é muito importante quando se trata de negociar, porque os parceiros não querem escrever tudo numa mensagem de e-mail, porque esse é um sinal de compromisso, e nem sempre eles querem estabelecê-lo naquele momento. Então, você começa as negociações, ou começa um problema falando. É para isso que as feiras de livros existem." (Fanny Thépot, gerente de sistemas da Berg Publishers)
Há tantas experiências nas feiras do livro quanto há pessoas a frequentá-las, de modo que seria impossível dar uma versão definitiva do que é uma feira e o que as pessoas fazem lá (Skov, 2006: 773). Algumas pessoas, como os editores, ficam mais ou menos fixos em seus estandes, embora possam visitar outros editores para discutir, por exemplo, uma coedição ou possibilidades de distribuição. Outros, como os negociadores de direitos, têm apenas uma mesa, quatro cadeiras e um armário com cabides. Outros, ainda, como os representantes comerciais, os distribuidores e os livreiros, não têm uma base e ficam em movimento o tempo todo. Um último grupo, que inclui os provedores de serviços, têm seus próprios estandes, mas também saem para atender os editores em seus respectivos estandes a fim de tentar vender-lhes seus serviços.

Varia muitíssimo o número de pessoas que cada editora envia às feiras de livros. Algumas grandes empresas têm dezenas de funcionários reunindo-se com clientes em potencial nas mesas de seus espaçosos estandes (onde geralmente discutem direitos de tradução, cinema, mídia etc.). Já as editoras pequenas e independentes podem ter apenas uma pessoa dando conta de todas as reuniões durante três a cinco dias. Por causa dos custos, as editoras tendem a enviar mais funcionários para seus mercados domésticos do que para uma feira distante.

Diferentes profissionais participam, geralmente, de tipos específicos de reunião durante a feira, porque trazem conhecimentos e experiências distintos. Então, o diretor geral de uma editora pode agendar meia dúzia de reuniões para discutir a distribuição (atual e

Dossiê Práticas Editoriais e Intermediações da Cultura

Arquivos do CMD, Volume7, N.1. Jan/Jun 2018 
potencial) de seus livros no exterior, na medida em que determinados países podem se mostrar problemáticos no que se refere a volume de negócios, pagamentos e descontos. Ele também pode discutir a coedição de alguns títulos de seu catálogo com, digamos, duas ou três editoras universitárias norte-americanas. Além disso, ele se encontra com editores de países como Argentina ou Itália que estejam interessados em seu catálogo ou queiram comprar direitos para publicação em um periódico de grande alcance. Esses editores estrangeiros também tentarão vender direitos de tradução de seus próprios catálogos para esse diretor geral. Este, ainda, atenderá empresas ligadas ao fornecimento e armazenamento de periódicos para bibliotecas, além de empresas especializadas em conversão de dados, fornecimento de softwares e desenvolvimento de sistemas. Por fim, ele certamente poderá conversar com dois ou três distribuidores asiáticos para discutir um projeto futuro (como o de uma enciclopédia). Uma semana após o término da feira, ele irá enviar a todos os membros de sua equipe um relatório substantivo (de nove a dez páginas) sobre as duas ou três dúzias de reuniões que ele manteve ao longo dos três dias em que esteve presente na feira juntamente com instruções sobre quem deve acompanhar quais casos e como agir em cada um deles.

Uma gerente de vendas e marketing, por sua vez, provavelmente terá até cinco dezenas de reuniões durante cinco dias inteiros, cada uma programada para durar meia hora, das 9 da manhã até, pelo menos, às 4 da tarde. Quase todas essas reuniões são préagendadas, embora geralmente haja duas ou três visitas inesperadas.
Essa gerente se concentra principalmente em vendas e direitos, encontros com distribuidores, representantes e gerentes de livrarias do mundo todo, a quem ela tentará vender os novos títulos que serão publicados naquele outono e no início da primavera seguinte. Durante esses encontros, ela poderá ter acesso a todo tipo de informação relevante ou irrelevante - do potencial de vendas a professores e estudantes de moda na Argentina ao caso de um russo que quer investir em editoras independentes, passando pelas políticas internas de uma universidade americana que podem influenciar a nomeação e o trabalho de um novo diretor para sua editora. Ela pode ser confrontada com a questão da nudez em uma ilustração de um livro para o caso de vendê-lo a países do Oriente Médio. Ela poderá, também, negociar direitos de tradução a um periódico esloveno, brasileiro ou bielorrusso. Ela pode, ainda, ficar sabendo de possíveis ofertas remanescentes nos Estados Unidos; da abertura de grandes livrarias em Bangkok ou Dubai; de como tirar proveito do orçamento das bibliotecas; ou de orçamentos suplementares e decisões dos comitês para compras acima de 200 mil ienes no Japão; da possibilidade de dividir, com outra editora acadêmica britânica, os custos para contratar um bom representante nos Estados Unidos; do mercado, dos nichos editoriais e do sistema de distribuição na Lituânia. Então, ao final de uma semana em Frankfurt, ela enviará um relatório de dez a doze páginas para seus colegas.

Embora uma ou duas dessas reuniões possam resultar em vendas imediatas (às vezes, acontece de um cliente encomendar de

Dossiê Práticas Editoriais e Intermediações da Cultura

Arquivos do CMD, Volume7, N.1. Jan/Jun 2018 
${ }^{8}$ Trata-se de uma variação das feiras de arte descritas por Thompson, nas quais as compras são combinadas feito posteriormente para evitar impostos locais.

${ }^{9}$ Owen (2006) fornece uma descrição detalhada dos vários termos que podem ser negociados, mas uma regra básica para a venda de direitos no setor de livros acadêmicos é a de pagar $10 \%$ do preço de capa, multiplicado pela tiragem. No entanto, isso depende também da percepção de um editor sobre um mercado externo e sobre quanto um comprador pode pagar (a esse propósito, cf. a discussão de Havens, 2011, sobre os direitos de programas de televisão)
5 a 10 mil libras em livros), a maioria delas termina com declarações verbais de intenção sobre compras futuras de títulos ${ }^{8}$. Por isso, é praticamente impossível dizer exatamente qual é o volume de negócios gerado durante uma feira de livros, embora o consenso geral é de que se gere algum volume. No caso das negociações de direitos, elas vêm em pacotes e é relativamente simples descobrir quantos títulos foram contratados para tradução, cinema, merchandising e assim por diante, e por quanto se negociou em cada caso9 ${ }^{9}$. No entanto, acordos de direitos não são necessariamente assinados na própria feira; eles podem ter sido conversados de antemão e apenas anunciados durante o evento.

No entanto, quando se trata de calcular os custos e benefícios das feiras no que se refere às vendas, a história é bem diferente. É interessante notar que as vendas estão totalmente ausentes das volumosas estatísticas publicadas nos sites da Reed Exhibitions e da Frankfurt Buchmesse - principalmente porque os participantes consideram difícil quantificar o que eles ganham em uma feira do livro. Alguns pedidos são feitos logo antes da feira, porque os interessados sabem que vão se encontrar dentro de uma semana Outros, por sua vez, ocorrem vários meses após o evento. De todo modo, esse comércio certamente não é desprezível. As feiras de livros oferecem aos seus participantes oportunidades de negociação com parceiros de longo prazo, além da aquisição de conhecimentos por meio da troca de informações sobre o mercado e pela visita aos estandes dos concorrentes, além da possibilidade de iniciar e manter relações sociais (Skov, 2006: 770).

\section{Visibilidade}

Uma feira comercial é semelhante a uma cidade, no sentido de que reúne pessoas diferentes que não se conhecem e cuja interação não depende de um roteiro único. Em vez disso, tal como ocorre com o pesquisador de campo, "múltiplos atores dotados de intenções individuais traçam múltiplas trajetórias que se entrelaçam para criar um espetáculo para além das exibições dos expositores" (Skov, 2006: 773). Ainda assim, como numa peça de teatro ou numa feira de moda, as feiras de livros, em certa medida, distraem a atenção de seu público com relação ao espetáculo que propiciam. Elas reúnem "um conjunto de empresas geograficamente dispersas, socialmente interligadas e culturalmente difusas num terreno neutro no qual elas restabelecem uma estrutura interna que é abstrata e relacional" (Skov, 2006: 768). Como parte dessa repactuação estrutural interna, a visibilidade é um dos principais objetivos daqueles que expõem nas e participam das feiras de livros (de modo similar ao que mostram Entwistle e Rocamora, 2011, sobre a London Fashion Week). São aspectos importantes: o momento e o local de uma feira; em que lugar você possui um estande e o tamanho dele; sua inclusão no catálogo da feira; os negócios que você fecha; e as festas que você promove ou frequenta.

Comecemos pelo momento, pela localização e pelo framing de uma feira de livros. As duas maiores feiras internacionais Londres e Frankfurt - estão programadas para coincidir com as duas temporadas de publicação, que começam em março e outubro.

Dossiê Práticas Editoriais e Intermediações da Cultura

Arquivos do CMD, Volume7, N.1. Jan/Jun 2018 
${ }^{10}$ Essa é a razão pela qual a Feira de Bolonha, realizada em março, é tão importante para esse setor específico do mercado. (N.T.: Em 2019, essa feira será realizada na primeira semana de abril.)

${ }^{11}$ A maior parte dos festivais não é proprietária de seu próprio local de realização (Mossberg and Getz, 2006: 319)

${ }^{12}$ Posteriormente, a Reed conseguiu contratar uma segunda sala de exposições em Earls Court, de modo exposições em Earls Court, de modo
que o espaço não está tão disputado como antes e os participantes parecem estar mais satisfeitos.
Frankfurt atende a esse critério, mas Londres não: abril é um pouco tarde para que os editores exponham seus lançamentos na feira de Londres, de modo que a maioria dos títulos tem sido contratada de antemão. Se tomarmos como exemplo os livros infantis, um editor local precisa de cinco a seis meses para adquirir os direitos de tradução, providenciar a tradução, contratar a impressão e fazer os exemplares chegarem às livrarias até setembro, a tempo da temporada de Natal. Como a feira de Londres acontece em abril, esse ciclo de publicação fica extremamente apertado ${ }^{10}$

Foi por esse motivo que, em 2006, a Reed Exhibitions mudou a feira de Londres do Earls Court para um novo local, Excel, do qual é em parte proprietária, nas Docklands ${ }^{11}$. Enquanto a feira ainda era pequena o suficiente para ser realizada no Olympia, que foi sua sede por dezessete anos, o calendário de março era perfeitamente adequado. No entanto, uma vez que a feira ficou grande demais para o Olympia, no início dos anos 2000, um novo local tornou-se necessário. Earls Court foi a solução encontrada, mas isso implicou um novo desafio: a feira não poderia mais ser realizada em março, porque Earls Court era, então, o local da Ideal Home Exhibition, evento que tem acontecido há mais de cem anos. Suas datas foram esculpidas em pedra.

Para resolver esse impasse, a Reed Exhibitions propôs que a feira do livro fosse para seu local nas Docklands. Todos os grandes expositores concordaram e a mudança foi feita; a feira foi marcada novamente para março. No entanto, tão logo a feira foi inaugurada, todos começaram a reclamar: o local era "no meio do nada". Levava "uma eternidade" para chegar lá, e mais que isso: não havia nenhum lugar agradável nas proximidades da feira para jantar e tomar um vinho. Como resultado, a Reed não teve escolha a não ser voltar para Earls Court e manter a feira em abril ${ }^{12}$.

Tudo isso tem a ver com a visibilidade, na medida em que a feira de Londres é o "habitat natural" da indústria editorial britânica:

Um dos motivos pelos quais as pessoas queriam que a feira permanecesse em Earls Court tinha a ver com status e visibilidade. Justamente porque ela é o local de se mostrar em sua terra natal, os editores britânicos consideram que tudo deve estar perfeito. Eles se preocupam com a maneira como serão vistos pelos visitantes estrangeiros... e isso significa ter bons restaurantes e bares ao redor, e também a própria feira. Foi por isso que a mudança para Docklands não deu certo. (Emma Lowe, gerente de vendas, London Book Fair, Reed Exhibitions)

No que concerne à posição e ao tamanho do estande de um expositor, pode-se dizer que tais aspectos têm enormes implicações para sua visibilidade no mundo editorial. Nesse sentido, as feiras de livros funcionam como "grafos", na medida em que traçam as posições relativas dos editores e de outros participantes num espaço abstrato (Skov, 2006: 768). Explica Emma Lowe:

Nosso trabalho é garantir que todos possam ser vistos. Isso significa que temos de certificar-nos de que os expositores não terão paredões e outras coisas do tipo, que os impeçam de ser notados pelas pessoas. Há uma altura máxima, por exemplo. Nada pode ter mais de 4 metros de altura. E se alguém quiser exceder esse limite, terá de passar por vários procedimentos administrativos que custam tempo e dinheiro antes da aprovação.

Dossiê Práticas Editoriais e Intermediações da Cultura

Arquivos do CMD, Volume7, N.1. Jan/Jun 2018 
${ }^{13} \mathrm{Na}$ Feira do Livro de Frankfurt, há uma sobretaxa de $10 \%$ para um estande de esquina, $15 \%$ para um estande na península e $20 \%$ para um estande de ilha. Um estande de península deve ter pelo menos 16 metros quadrados de área, e o de ilha, 100 metros quadrados.

${ }^{14}$ Como Skov (2006: 766) assinala, "o recinto de feiras sempre carrega traços de sua própria construção".

15 Os expositores que montam seus próprios estandes em Frankfurt têm que pagar 750 euros para acessar o local da exposição a partir da quintafeira antes do início da feira.
A importância da localização do estande e da visibilidade podem ser vistas nos mecanismos de precificação. Um estande de corredor custa menos que um estande de esquina, que, por sua vez, custa menos que um estande península (de frente a três corredores) que custa menos que um estande de ilha ${ }^{13}$. Uns quatro ou cinco diferentes "conjuntos" ou "pacotes" de mobiliário estão disponíveis para locação, com diferentes qualidades de mesas e cadeiras, além de itens adicionais de elétrica e mobília, em uma escala de preços que varia de 158 a 642 euros em Frankfurt ${ }^{14}$. Novamente, diz Emma Lowe:

Outro aspecto a ser notado é o fato de que cada vez mais pessoas estão construindo seus próprios estandes para exibição. No ano passado, cerca de 900 metros quadrados de espaço dos estandes - isto é, de 6 a $7 \%$ do total - foi construído de forma independente (apesar de que, quando um arquiteto como meu marido dá uma olhada, ele se pergunte por que eles não conseguiram desenvolver um design adequado e decente!). Isso mostra que é importante cuidar da aparência e fazer a diferença. A Reed ganha dinheiro fornecendo conjuntos especialmente projetados para expositores estrangeiros, como a Microsoft, que contrata esse serviço antecipadamente e apenas vai à feira, sem ter que se preocupar com detalhes.

Aqui, a visibilidade equivale a uma espécie de consumo conspícuo, na medida em que as editoras grandes e ricas esbanjam dezenas de milhares de libras em estandes especialmente projetados - algo que também encontramos nos mercados globais de televisão discutidos por Havens (2011). ${ }^{15}$ A única vantagem desse gasto é que os expositores podem usar o mesmo design e os mesmos equipamentos em outras feiras ao redor do mundo e, pelo menos na visão de um frequentador comum, estabelecer uma forma de "identidade de marca". A esse cenário de semelhança que permite a comparação direta entre empresas diferentes, Lise Skov chama "condição de comparabilidade". Ela argumenta que as feiras permitem aos editores

[...] aparecerem livres de uma história, uma geografia e um contexto social; todos os vestígios da produção são removidos das amostras. O que é visível no estande na feira é apenas a posição atual da empresa no mercado em relação a outras empresas. Na medida em que uma empresa tem uma reputação, essa reputação deve ser reencenada por meio de adereços modulares. (Skov, 2006: 767)

Assim, os estandes fornecem um mapa das relações de poder entre os jogadores dentro do campo editorial em si e também entre este e outros campos relacionados. Não surpreende, portanto, que grandes editoras demonstrem claras preferências com relação ao local onde exporão, como Emma Lowe explica:

Este ano (2008), toda a exposição foi planejada em torno da Hachette, porque eles foram os primeiros a reservar um espaço com uma forma e um tamanho específicos - três fileiras depois da entrada principal, de um dos lados do corredor central. Em seguida, veio a Random House, que quis um bloco três fileiras atrás, mas, por algum motivo, não no bloco oposto ao da Hachette, no corredor central, e a um bloco de distância. Felizmente a HarperCollins quis o ponto livre em frente à Hachette, mas obviamente tivemos que consultar a Hachette antes.

Dossiê Práticas Editoriais e Intermediações da Cultura 
E isso gera um aborrecimento, porque existem todas essas empresas subsidiárias - como a Octopus exibindo com a Hachette, e todos eles precisaram ser consultados para garantir que não houvesse nenhum conflito ou algo do tipo, para somente então aprovar a HarperCollins. Demorou umas três semanas para definir essa configuração. Somente depois disso é que pudemos começar a encaixar os pedaços com outras contas-chave.

Então, como é feita a alocação desses espaços quando eles são tão valiosos?

Nós temos um sistema de pontuação que usamos ao alocar espaço para os expositores. Do total, $50 \%$ vai para o número de anos que a editora vem para a feira, e 50\% para o tamanho do estande que eles contratam. É muito difícil ser justo, mas temos que tentar, e esta é a única maneira pela qual podemos fazer isso. Aos expositores que se queixam, nós pedimos que proponham outro método de avaliação, mas ninguém fez isso com êxito ainda. Temos que recompensar a lealdade. No que se refere aos expositores, não é uma questão de quantos livros ou direitos eles vendem, mas de quantos anos eles têm participado em Frankfurt ou Londres.

Basicamente, é uma questão de "usucapião". O problema surge quando uma empresa decide expandir um pouco seu espaço, como a Wiley querendo o resto do seu bloco no próximo ano. Isso significa que Murdoch, que ocupa esse espaço, terá que sair - não que eles já saibam disso. E isso significa também que eu terei de começar a faze malabarismos com os outros estandes. E um efeito cascata. Alguns estão felizes em estar juntos - é o caso das equipes de promoção, por exemplo -, mas outros, como as empresas de soluções (empresas de frete como DHL, UPS etc.), preferem que haja separação.
E qual é a questão aqui?

As pessoas têm medo de que os concorrentes roubem seus clientes ou lhes passem a perna de alguma forma, com relação a ideias que eles tiveram. Então, há questionamentos que eu tenho de responder do tipo "Onde é que fulano está localizado?", porque a pessoa interessada quer ou não ficar perto de fulano de tal. Tem muito de diplomacia nisso. Quero dizer, eu sabia tudo sobre aquelas "compras a rodo" da Pearson-Penguin muito antes de serem anunciadas oficialmente, porque a nova empresa tinha de ter um estande conjunto e planejar o espaço e o design para a próxima feira de Londres.

Aqui podemos ver o lado reverso da visibilidade: a invisibilidade. As empresas querem ser vistas, mas apenas por alguns e não por outros.

Um terceiro aspecto da visibilidade numa feira de livros é o catálogo oficial da feira, que é considerado uma espécie de Bíblia, um "Quem é quem" do mundo editorial, no qual todos os expositores querem ser incluídos. Esse catálogo traz uma lista de todos os expositores em ordem alfabética. Cada entrada inclui nome, localização do estande, endereço comercial, números de telefone e fax, endereço de e-mail e uma descrição da empresa de até cinco linhas, com até três nomes de pessoas para contato (que são listadas em uma seção separada). Esse produto enumera todos os expositores estrangeiros e classifica todos os expositores em categorias de produtos (computação, ecologia, gastronomia etc.). Assim, os indivíduos ganham pelo menos duas menções, e os expositores, três

Dossiê Práticas Editoriais e Intermediações da Cultura

Arquivos do CMD, Volume7, N.1. Jan/Jun 2018 
${ }^{16}$ N.T.: No original, Moeran contrasta o conceito de value ao de worth discutidos por Lewis Hyde. Para esse autor, enquanto a mercadoria tem um valor (value), a dádiva tem apenas um valor (worth). Nesse sentido, o preço que se dá a um objeto, tornando-o mercadoria é uma forma de reduzir seu worth a uma quantia que o torna negociável e intercambiável por outros. Em português, optou-se por indicar apenas as aparições de worth com o termo original em inglês, ao passo que as menções a value são indicadas pela tradução literal, valor (N.T.) (uma vez que são incluídos por meio afiliação individual na seção “Quem é quem”).

Em quarto lugar, há os negócios realizados na feira. Se, por um lado, eles são propagados dentro dos diferentes segmentos da indústria (ou seja, as ofertas de livros comerciais são logo conhecidas entre as editoras que atuam nesse nicho, e assim por diante), o jornal da feira divulga diariamente, para a indústria como um todo, os detalhes dos negócios - incluindo aquisições de empresas, compras de títulos de livros, leilões e adiantamentos, adaptações para o cinema, contratos de direitos estrangeiros, prêmios da indústria, iniciativas de comércio virtual e inovações digitais.

Finalmente, há as festas. Os participantes das feiras são frequentemente convidados a pelo menos uma das inúmeras festas e recepções realizadas nos estandes dos expositores - seja para lançar um novo livro, comemorar 100 anos de atividade (Mills \& Boone), ou apenas para compartilhar sua felicidade em estar lá! Tais recepções são consideradas muito importantes, porque proporcionam um ambiente descontraído no qual as pessoas podem se encontrar, trocar informações, fazer fofocas e, de modo geral, mostrar que são membros plenos da comunidade editorial. É importante, portanto, que os participantes do campo editorial apareçam - ou seja, que vejam e sejam vistos -, pois as festas marcam diferentes categorias de "insiders" e "status de pertencimento", como também argumentam Havens (2011) e Entwistle e Rocamora (2011).

\section{Conclusão}

Antropólogos da economia há muito tempo têm se interessado pelo modo como são atribuídas, aos objetos materiais, qualidades que não podem ser reduzidas à necessidade material que suprem ou ao seu equivalente monetário (Bell and Werner, 2004: xi). Esse é o principal argumento apresentado também aqui e nos vários trabalhos reunidos em Moeran e Pedersen (2011).

Os valores são a razão de ser das feiras. Uma feira de livros, portanto, é um torneio de valores, e não um torneio de valor, porque não há um valor único considerado por todos os participantes, com suas múltiplas trajetórias nas feiras de Frankfurt, Londres ou em qualquer outra feira do livro (ou de outra mercadoria). Pelo contrário, como foi apontado anteriormente, o campo editorial é caracterizado por quatro tipos de recursos. É nessas diferentes formas de capital econômico, social (ou humano), simbólico e intelectual que diferentes tipos de valor (value) - ou valor (worth) (Hyde, 1983: 60) ${ }^{16}$ - são criados, contestados e sustentados nas feiras de livros. Todos os participantes mencionam o estabelecimento de relações sociais como uma função crucial das feiras do livro. Eles também comentam as dimensões simbólicas da localização, do design e do tamanho do estande; os negócios realizados por meio de canais de comunicação formais e informais; e as festas das quais participaram ou ouviram falar. Por fim, os editores mostraram-se interessados em negociar os ativos

Dossiê Práticas Editoriais e Intermediações da Cultura

Arquivos do CMD, Volume7, N.1. Jan/Jun 2018 
${ }^{17}$ Appadurai (1986: 57) referiu-se a isso como "desvios calculados que podem levar a novos caminhos no fluxo de mercadorias". intelectuais - ou seja, a criatividade - de seus autores como transações comerciais. Essa combinação de valores sociais, simbólicos e de apreciação é convertida de valor (worth) inestimável a preço, ou troca econômica, valor. É essa equação que é primeiro esboçada e, então, calculada, negociada e acordada na feira do livro.

O que os participantes acreditam que seja o mundo editorial e o que eles sentem que podem exigir desse mundo: eis o que está em jogo em todas as feiras do livro do mundo. Valores sociais, simbólicos e apreciativos só podem existir e operar efetivamente dentro dessa teia de relações sociais. O valor econômico é, portanto, essencialmente "negativo", no sentido de que só pode assumir significado em contraste e relação com outros valores (de Saussure, 1983: 116-8), que também podem abranger as propriedades materiais/técnicas e de utilidade dos objetos. Juntamente com os outros valores citados, estes constituem um campo de valores, cuja contestação e negociação dão origem ao valor propriamente dito (de troca mercantil) (cf. Moeran, 2004: 266-70).

As feiras internacionais do livro - tal como as semanas de moda, os prêmios Grammy e assim por diante - claramente configuram um campo específico (de publicação, moda ou música). No entanto, esses eventos não necessariamente fazem isso de maneira idêntica, pois cada "torneio de valores" tende a enfatizar alguns valores em detrimento de outros. Por exemplo, embora as feiras de livros exibam alguns elementos do comportamento ritual, elas não moldam a evolução do campo da mesma maneira, por exemplo, que o Oscar para o caso do cinema (Faulkner e Anderson,
1987; Levy, 1987: 269) ou o Julgamento de Paris para o universo da degustação de vinhos, discutido por Anand (2011). É verdade que dois prêmios literários (o Prêmio da Paz do Comércio de Livros Alemão e o Prêmio do Livro Alemão) são anunciados durante a realização da feira de Frankfurt; além disso, o Prêmio Nobel de Literatura coincide mais ou menos com ela. Porém, de modo geral, grandes prêmios literários não estão ligados a feiras de livros. Tais prêmios privilegiam determinados players e constroem hierarquias de prestígio no campo editorial. Eles também têm um efeito sobre as vendas de ficção, os adiantamentos e os contratos, mas tal efeito não é tão intenso como ocorre, possivelmente, com os prêmios Grammy ou com o Booker Prize, em termos de sua influência no comércio, de apelo ao gosto popular e da criação de uma nova categoria literária distintiva (ver também Watson e Anand, 2006; Anand e Jones, 2008) $)^{17}$.

Em contrapartida, em vários outros aspectos as feiras de livros se aproximam muito da definição de "torneio de valores" de Appadurai. Aqui, novamente, valores simbólicos, sociais e de apreciação entram em cena. Em primeiro lugar, trata-se de eventos periódicos complexos que ocorrem em lugares especiais e momentos especiais. Eles são "tanto um ritual quanto um evento único", um "show" que tem um "lugar fixo de encontro" separado em termos de tempo, lugar, ambientação e elementos acessórios (Malinowski, 1922: 85; Baudrillard, 1981: 116; ver também Smith, 2011). Com sua estrutura vedada e sem janelas e suas construções e móveis especiais, as salas de exposição separam a feira do livro do mundo

Dossiê Práticas Editoriais e Intermediações da Cultura

Arquivos do CMD, Volume7, N.1. Jan/Jun 2018 
18 Conheço uma parte da literatura antropológica sobre direitos de propriedade intelectual, em especial de Marilyn Strathern, mas não irei abordá-la aqui, uma vez que minhas observações foram elaboradas com o intuito de iniciar novas discussões, mais do que para fornecer um relato definitivo sobre os significados do copyright exterior. Além disso, como mencionado antes, as feiras fornecem, em termos espaciais, um mapa dos principais agentes e instituições do campo editorial (diferentes tipos de editoras, vendedores de direitos, prestadores de serviços, agentes, mídia) e, assim, incorporam esse campo mais amplo à medida que produzem e legitimam tanto o próprio campo quanto as posições dos agentes dentro dele (Entwistle e Rocamora, 2006: 736). Tal como acontece com os desfiles de moda, apenas aqueles que já têm uma posição reconhecida no campo podem ter acesso a feiras como as de Frankfurt ou Londres. O fechamento é, portanto, um aspecto importante da consagração e está condicionado por uma série de limites, que distinguem as várias categorias de insiders e outsiders, e vigiado por gatekeepers que permitem ou barram o acesso à feira.

Em terceiro lugar, as feiras do livro servem para definir a indústria editorial como uma comunidade (ou "família", como é comumente referida), uma vez que proporcionam um espaço incorporado de práticas onde a visibilidade e o reconhecimento mútuo levam a um sentimento de pertença (Entwistle e Rocamora, 2006: 743, 749). Essas feiras mobilizam questões que dizem respeito a fazer parte dessa comunidade, gerenciam as relações interpessoais dos participantes e, até certo ponto, regulam seu comportamento (incluindo a linguagem intragrupal e os códigos de vestimenta) (Smith, 1989: 51) durante uma série de performances face a outros insiders da indústria.

Por fim, embora as feiras de livros sejam momentos apartados da rotina da vida econômica cotidiana, o que acontece ali (a venda de direitos, os compromissos dos agentes, representantes, distribuidores etc.) tem consequências dentro das realidades mais mundanas do campo editorial como um todo. Os torneios de valores caracterizam-se pelo fato de que fazem uso de uma "moeda" diferente do dinheiro propriamente dito. Isso certamente ocorre em eventos de publicidade, onde a moeda em questão é a conta (Moeran, 1993: 88-9), e nos desfiles de moda, onde a "coleção" constitui a moeda por meio da qual a produção sazonal de um designer é avaliada. Pode-se dizer que a "moeda" nas feiras do livro são os direitos derivados dos ativos de propriedade intelectual, uma vez que esse é o principal símbolo de valor para os editores. Os direitos não estão necessariamente sujeitos à lei da oferta e da demanda, porque muitas vezes dependem do gosto pessoal (é por isso que os agentes que negociam direitos passam anos e anos cultivando relações pessoais e aprendendo sobre os gostos de seus compradores). Os direitos estão ligados ao estatuto, à classificação, à fama e à reputação de autores e editoras, bem como dos indivíduos responsáveis por comprá-los e vendê-los. Em última análise, no entanto, eles dependem das vendas.

O copyright - ou seja, o direito de reproduzir um trabalho criativo - está, obviamente, consagrado na lei. Porém, há mais nos direitos autorais do que suas repercussões legais e financeiras ${ }^{18}$. Em sua discussão sobre o célebre ensaio de Mauss sobre a dádiva, Maurice Godelier (2004: 19) traça uma distinção entre a venda de mercadorias (que são, portanto, alienáveis e alienadas), o ato de dar objetos de presente (que são inalienáveis, mas alienados) e o ato de

Dossiê Práticas Editoriais e Intermediações da Cultura

Arquivos do CMD, Volume7, N.1. Jan/Jun 2018 
19 No original, production editor. Moeran se refere ao profissional de alto escalão envolvido diretamente na concepção material e intelectual do livro, em contraste com o gerente editorial (managing editor) e o editor de aquisição (acquisition editor ou commissioning editor). Há bastante variação no modo como tais guardar objetos sagrados (que, assim, se tornam inalienáveis e não alienados). Por exemplo, em algumas partes da Melanésia, certos objetos (conhecidos como kitoum) pertencem a uma linhagem ou indivíduo até serem lançados em um caminho de troca de kula e são passados de um recipiente para outro (como vaygu'a). No entanto, tais objetos continuam pertencendo ao doador original, que pode, em teoria, pedir ao destinatário temporário para devolvê-lo. Em outras palavras, o dono de um kitoum-cum-vaygu'a cede os direitos de uso de modo a permitir que outras dádivas sejam feitas, mas não a propriedade como tal (Godelier, 2004: 15). Assim, certos objetos de valor são alienados, mas permanecem como propriedade inalienável do proprietário original.

Aqui, o paralelo com o copyright é evidente. Quando um autor declara seu direito moral sobre um trabalho escrito, supõe-se que a criatividade envolve a imanência de uma pessoa (ou criador) numa coisa (o trabalho criativo) - uma suposição sustentada pela lei de direitos autorais (Feather, 2006: 162). Ao permitir a publicação de seu trabalho, o autor atribui a uma editora, por um período limitado de tempo, o direito de copiar esse trabalho; a editora, por sua vez, transfere esse direito e direitos subsidiários associados (adaptações, dramatizações e serializações) para outros agentes da cadeia editorial. Esses direitos geralmente retornam à editora e, daí, ao autor após um período de tempo estipulado e permanecem com o autor até cinquenta anos após sua morte, quando o trabalho se torna "alienável” - por meio da livre circulação no domínio público. O copyright é, portanto, algo que é dado-enquanto-mantido (Weiner
1992). Nesse sentido, a "venda" de direitos na feira do livro não separa completamente coisa e pessoa; em vez disso, há um elemento de dádiva, uma vez que algo do criador permanece no trabalho criativo trocado. Os direitos autorais e outros direitos de propriedade, portanto, ocupam "um sensato meio-termo entre dom e mercadoria; eles conseguem honrar o desejo de enriquecimento individual e, ao mesmo tempo, reconhecem as necessidades da comunidade" (Hyde, 1983, p. 81)

Existe, aqui, uma ironia. Em muitos aspectos, as feiras internacionais do livro dão destaque à venda de direitos sobre obras criativas. Nesse processo, contudo, elas desviam a atenção do fato de que nem o autor, nem o editor executivo ${ }^{19}$ (que é a pessoa da indústria editorial responsável por cuidar do processo criativo) costumam frequentar essas feiras. Em vez disso, são as pessoas envolvidas com vendas e marketing (além, ocasionalmente, do editor de aquisição) que circulam e lidam com a distribuição de direitos. Uma vez que "as mercadorias devem se mover entre esferas reciprocamente independentes" (Hyde, 1983: 201), pode-se dizer que a feira é projetada para tornar visível o livro como uma mercadoria e para tornar invisível a inalienabilidade dada-enquantomantida do livro como dádiva. É na sombra da dádiva que a mercadoria livro é produzida, distribuída, vendida e lida. Sob tais circunstâncias, não é de surpreender que os participantes valorizem muito as relações sociais mantidas na feira. Elas estão no coração da troca de dádivas (Mauss, 1966), através da qual a proximidade espacial (a feira do livro) torna-se vida social (a comunidade

Dossiê Práticas Editoriais e Intermediações da Cultura

Arquivos do CMD, Volume7, N.1. Jan/Jun 2018 
editorial). Como diz Lewis Hyde (1983: 69), “dádivas implicam relações".

\section{Agradecimentos}

Este texto é uma versão modificada de um artigo publicado no Journal of the Royal Anthropological Institute na edição da primavera de 2010. Gostaria de agradecer ao Conselho de Pesquisa Estratégica da Dinamarca por financiar as viagens de campo para as Feiras do Livro de Frankfurt, Londres e Tóquio, além da pesquisa e elaboração deste artigo como parte das atividades do grupo Oreative Encounters. Também tenho uma grande dívida para com Kathryn Earle e Veruschka Selbach, da Berg Publishers, que me permitiram participar de suas negociações na Feira do Livro de Frankfurt em outubro de 2007 e na Feira do Livro de Londres em abril de 2008 , bem como a Bridget Shine, da Independent Publishers Guild (IPG), por aceitar minha presença no estande do IPG na Feira do Livro de Frankfurt em outubro de 2009

\section{Referências}

ANAND, N.; JONES, B. "Tournament rituals, category dynamics, and field configuration: the case of the Booker Prize", Journal of Management Studies, vol. 45 n. 6, p. 1.036-60, 2008.

ANAND, N.; WATSON, M. "Tournament rituals in the evolution of fields: the case of the Grammy Awards", Academy of Management Journal, vol. 47, p. 59-80, 2004

ANAND, N. "The retrospective use of tournament rituals in field configuration: the case of the 1976 'Judgement of Paris' wine tasting”. In: MOERAN, B.; PEDERSEN, J. S. (Eds.). Negotiating Values in the Creative Industries. Fairs, Festivals and Competitive Events. Cambridge/Nova York: Cambridge University Press, 2011. p. 321-333.

APPADURAI, A. 1986. "Introduction: commodities and the politics of value", in: (Ed.). The Social Life of Things. Cambridge: Cambridge University Press, 1986, p. 3-63.

BARBATO, M.; MIO, C. "Accounting and the development of management control in the cultural sphere: the case of the Venice biennale", Accounting, Business and Financial History, vol. 17, p. 187-208, 2007.

BAUDRILLARD, J. The Political Economy of the Sign. St. Louis, MO: Telos, 1981.

BELL, D.; WERNER, C. (Eds.). Values and Valuables: from the Sacred to the Symbolic. Walnut Creek, CA: Altamira, 2004.

BERNE, C.; GARCÍA-UCEDA, M. E. 2008. "Criteria involved in evaluation of trade shows to visit", Industrial Marketing Management, vol. 37, p. 565-79, 2008

BOURDIEU, P. The Field of Cultural Production: Essays on Art and Literature. Cambridge: Polity, 1993.

CAVES, R. Creative Industries: Contracts Between Art and Commerce. Cambridge, MA: Harvard University Press, 2000.

CLARK, G. Inside Book Publishing. 3. ed. Londres: Routledge, 2001

ENTWISTLE, J.; ROCAMORA, A. "The field of fashion materialized: a study of London Fashion Week", Sociology, vol. 40 n. 4, p. 735-51, 2006.

"Between art and commerce: London Fashion Week as trade fair and fashion spectacle". In: MOERAN, B.; PEDERSEN, J. S. (Eds.). Negotiating Values in the Creative Industries. Fairs, Festivals and Competitive Events. Cambridge/Nova York: Cambridge University Press, 2011. p. 249-69.

Dossiê Práticas Editoriais e Intermediações da Cultura

Arquivos do CMD, Volume7, N.1. Jan/Jun 2018 
EVANS, O. "Border exchanges: the role of the European film festival”, Journal of Contemporary European Studies, vol. 15, p. 23 33, 2007.

FAULKNER, R.; ANDERSON, A. 1987. 'Short-term projects and emergente careers: evidence from Hollywood', American Journal of Sociology, vol. 92, p. 879-909, 1987.

FEATHER, J. A History of British Publishing. 2. ed. Londres/Nova York: Routledge, 2006

FLOOD, J. “'Omnium totius orbis emporiorum compendium': the Frankfurt fair in the early modern period". In MYERS, R., HARRIS M. e MANDELBROTE, G. (Eds.). Fairs, Markets and the Itinerant Book Trade. Delaware/Londres: Oak Knoll Press/British Library, 2007, pp. 1-42.

GLYNN, M. "Configuring the field of play: how hosting the Olympic games impacts civic Community", Journal of Management Studies, vol. 45 n. 6, p. 1.117-46, 2008

GODELIER, M. 2004. "What Mauss did not say: things you give, things you sell, and things that must be kept". In: WERNER, C.; BELL, D. (Eds.). Values and Valuables: from the Sacred to the Symbolic. Walnut Creek, CA: Altamira, 2004, p. 3-20.

HAVENS, T. "Inventing universal television: restricted access, promotional extravagance, and the distribution of value at globa television markets". In: MOERAN, B.; PEDERSEN, J. S. (Eds.) Negotiating Values in the Creative Industries. Fairs, Festivals and Competitive Events. Cambridge/Nova York: Cambridge University Press, 2011. p. 145-68.

HYDE, L. The Gift: Imagination and the Erotic Life of Property. Nova York: Vintage, 1983.

LAMPEL, J.; MEYER, A. "Field-configuring events as structuring mechanisms: how conferences, ceremonies, and trade shows constitute new technologies, industries, and markets", Journal of Management Studies, vol. 45 n. 6, p. 1.025-35, 2008.
LEVY, E. And the Winner Is.. The History and Politics of the Oscar Awards. Nova York: Ungar, 1987

MALINOWSKI, B. Argonauts of the Western Pacific. Londres: G. Routledge and Sons, 1922.

MAUSS, M. The Gift: Forms and Functions of Exchange in Archaic Societies. Londres: Cohen and West, 1966.

MOERAN, B. 1993. "A tournament of value: strategies of presentation in Japanese advertising", Ethnos, vol. 58 n. 1-2, p. $73-$ 94, 1993.

"Women's fashion magazines: people, things, and values". WERNER, C.; BELL, D. (Eds.). Values and Valuables: from the Sacred to the Symbolic. Walnut Creek, CA: Altamira, 2004, p. 25781.

MOERAN, B.; PEDERSEN, J. S. (Eds.). Negotiating Values in the Creative Industries. Fairs, Festivals and Competitive Events. Cambridge/Nova York: Cambridge University Press, 2011.

MOSSBERG, L.; GETZ, D. 2006. "Stakeholder influences on the ownership and management of festival brands", Scandinavian Journal of Hospitality and Tourism, vol. 6 n. 4, p. 308-26, 2006.

OWEN, L. Selling Rights. 5. ed. Londres/Nova York: Routledge, 2006.

POWELL, W. Getting into Print: the Decision-making Process in Scholarly Publishing. Chicago: Chicago University Press, 1985.

POWER, D.; JANSSON, J., "Cyclical clusters in global circuits: overlapping spaces in furniture trade fairs", Economic Geography, vol. 84 n. 4, p. 423-48, 2008.

SAUSSURE, F. de. Course in General Linguistics. Londres: Duckworth, 1983.

SKOV, L. "The role of trade fairs in the global fashion business", Current Sociology, vol. 54 n. 5, p. 764-83, 2006.

SMITH, C. Auctions: the Social Construction of Value. Londres: Harvester Wheatsheaf, 1989.

Dossiê Práticas Editoriais e Intermediações da Cultura

Arquivos do CMD, Volume7, N.1. Jan/Jun 2018 
"Staging auctions: enabling exchange values to be contested and established". In: MOERAN, B.; PEDERSEN, J. S (Eds.). Negotiating Values in the Creative Industries. Fairs,

Festivals and Competitive Events. Cambridge/Nova York: Cambridge University Press, 2011. p. 94-118.

THOMPSON, D. The \$12 Million Stuffed Shark: the Curious Economics of Contemporary Art and Auction Houses. Londres: Aurum, 2008.

"Art fairs: the market as medium". In: MOERAN, B. PEDERSEN, J. S. (Eds.). Negotiating Values in the Creative Industries. Fairs, Festivals and Competitive Events. Cambridge/Nova York: Cambridge University Press, 2011. p. 5972.

THOMPSON, J. Books in the Digital Age. Cambridge: Polity, 2005.

WATSON, M.; ANAND, N. "Award ceremony as an arbiter of commerce and canon in the popular music industry", Popular Music, vol. 25 n. 1, p. 41-56, 2006

WEIDHAAS, P. A History of the Frankfurt Book Fair. Toronto: Dundurn, 2007.

WEINER, A. Inalienable Possessions: the Paradox of GivingWhile-Keeping. Berkeley/Los Angeles: University of California Press, 1992.

WELLER, S. "Beyond 'global production networks': Australian Fashion Week's trans-sectoral synergies", Growth and Change, vol. 39 n. 1, p. 104-22, 2008 